FACULDADE DE CIÊ NCIAS ECONÔ MICAS DA UFRGS

REESTRUTURAÇÁ O DA PRODUÇÁ O AGRICOLA NO RIO GRANDE DO SUL, DE 1970 A 1996 E UMA ESTIMAÇȦ O PARA 2012 TIAGO WICKSTROM ALVES

A CRIMINALIDADE NA RECIAO METROPOLTANA DE SALVADOR JOSÉ CARRERA FERNANDEZ, LUIZ FERNANDO LOBO

COMPEIITIVIDADE INTERNACIONAL EM SOFTWARE: UM ESTUDO SOBRE A EXPERIÊNCIA DE FLORIANÓ POLIS HOVÉDO NUNES LINS

MODELOS DE ORGANIZAÇẢ O E REPARTIÇẢ O DE RENDAS NA CADEIA PRODUTIVA DO GÁS NATURAL.

HELder QUEIROZ PINTO Jú NIOR, RODOLFO TORRES dOS SANTOS

REGIMES MONETÁ RIOS E DIVIDA PÚ BLICA: UMA ANÁ LISE DE MECANISMOS ALTERNATIVOS DE COORDENAÇÃO MACROECONÓ MICA

manoel Carlos de Castro Pires

ECONOMIA DOS RECURSOS NATURAIS E SEUS INDICADORES DE ESCASSEZ: UMA QUESTÃ O DE SUSTENTABILIDADE ANDREA SALES SOARES DE AZEVEDO MELO

O ECOPROTECIONISMO AGRICOLA NA UNIĀ O EUROPEIA E SEUS POSSIVEIS IMPACTOS SOBRE A ECONOMIA BRASILEIRA Rodrigo daniel Feix, Clá udio R. Fóffano Vasconcelos

PADRÓ ES DE DESENVOLVIMENTO, FUNÇ Ó ES ESTATAIS E ENDIVIDAMENTO NO CAPITALISMO CONTEMPORÁNEO paulo Balanco, Eduardo Costa Pinto

A INTERNACIONALIZAÇÃO DO VAREJO A PARTIR DOS CASOS WAL-MART E CARREFOUR

Armando joảo dalla Costa

UMA ANÁ LISE ECONOMÉTRICA DO FUTEBOL BRASILEIRO ARI Francisco de Araujo JR, Clá udio D. SHIKIDA, LEONARDO M. MONASTERIO

O BRASIL E A ECONOMIA INTERNACIONAL: RECUPERAÇÃ O E DEFESA DA AUTONOMIA NACIONAL

RESENHA DE ALEXANDRE CÉ SAR CUNHA LEITE

REGIMES MONETÁ RIOS: TEORIA E A EXPERIÊNCIA DO REAL ResenHa de Fernando Ferrari Filho

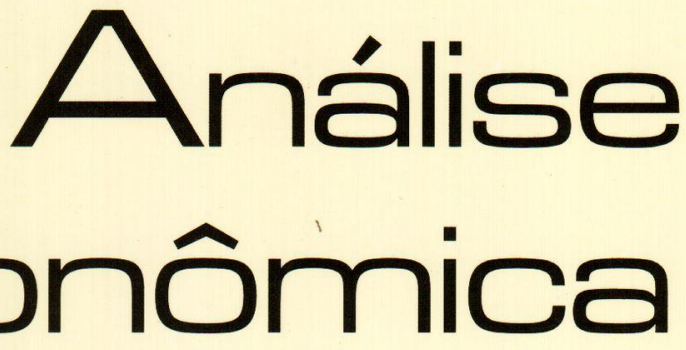


Universidade Federai. do Rio Grande do Sul Reitor: Prof José Carlos Ferraz Hemnemann

Facul dade de Cuéncias Economicas

Diretor: Prof. Gentil Corazza

Ceniro de Estudos f Prequisas Economicas

Diretor: Prof. Lovois de Andrade Miguel

Depariamenio de Crências Economicas

Chefe: Prof Ricardo Dathein

Departamento de Cîncias Coniábeis f A tuaria Chefe: Prof. Ceno Odilo Kops

Curso de Pós-Graduaçó em Economia

Coordenador: Prof. Fernando Ferrari Filho

Curso de Pos-Grainaça em Desenvolvimento RuRAI

Coordenador: Prof. Paulo Dabdab Waquil

Conseluo Eni tokial: André Moreira Cunha (UFRGS) Carlos G. A. Mielitz Netto (UFRGS), Carlos Henrique Hom (UFRGS). Eduardo A. Maldonado Filho (UFRGS). Eleutério F S. Prado (USP), Eugênio Lagemann (UFRGS), Fernando Cardim de Carvalho (UFRJ). Femando Ferrari Filho (UFRGS), Fernando de Holanda Barbosa (FGV/RJ), Flávio Augusto Ziegelmann (UFRGS), Flávio Vasconcellos Comin (UFRGS), Gentil Corazza (UFRGS), Giácomo Balbinot to Neto (UFRGS), Gustavo Franco (PUC/RJ) Hélio Henkin (UFRGS), Jan A. Kregel (UNCTAD), João Rogério Sanson (UFSC), Joaquim Pinto de Andrade (UnB), Júlio César Oliveira (UFRGS), Luiz Estrella Faria (UFRGS), Luiz Paulo Ferreira Nogueról (UFRGS), Marcelo S Portugal (UFRGS), Maria Alice Lahorgue (UFRGS), Octávio Augusto Camargo Conceicão (UFRGS), Paul Davidson (University of Tennessee), Paulo D. Waquil (UFRGS), Pedro C. D. Fonseca (UFRGS), Philip Arestis (University of Cambridge), Ricardo Dathein (UFRGS) Ronald Otto Hillbrecht (UFRGS), Sabino da Silva Porto Jr (UFRGS), Sérgio M. M. Monteiro (UFRGS), Stefano Florissi (UFRGS) e Werner Baer (University of IIIinois at Urbana - Champaign)

Comissão Emroniai: Eduardo Augusto Maldonado Filho, Fernando Ferrari Filho, Hélio Henkin. Marcelo Savino Portugal, Paulo Dabdab Waquil e Sérgio Marley Modesto Monteiro.

EnIrok: Sérgio Marley Modesto Monteiro

Ediror Adjun ro: Hélio Henkin

Secretário: Emerson Douglas Neves

REVISÃo DE IEX ros: Vanete Ricacheski

Emioração: Núcleo de Editoração e Criação da

Gráfica da UFRGS - Janaína Horn e Junia Saedt

Fundador: Prof Antonio Carlos Santos Rosa
Os materiais publicados na revista Análise Econômica são da exclusiva responsabilidade dos autores. É permitida a reprodução total ou parcial dos trabalhos, desde que seja citada a fonte. Aceita-se permuta com revistas congêneres. Aceitam-se, também, livros para divulgacão, elaboraça de resenhas e recensões Toda correspondência: material para publicação (vide normas na terceira capa), assinaturas e permutas devem ser dirigidos ao seguinte destinatário:

Prof. Sérgio Marley Modesto Monteiro Revista Andilse Económica - Av. João Pessoa, 52 CEP 90040-000 PORTO ALEGRE - RS, BRASIL Telefones: (051) $33163513 / 33164164$

Fax: (051) 33163990 - E-mail: rae@vortex ufrgs.br

A Revista Análise Econômica agradece a colaboração dos pareceristas do número 43, abaixo relacionados:

Adalmir Antonio Marquetti

André Moreira Cunha

Carlos José Caetano Bacha

Carlos Mielitz. Netto

Clailton Ataídes de Freitas

Claudio Roberto Fóffano Vasconcelos

Eduardo Ernesto Filippi

Eduardo Pontual Ribeiro

Eleuterio Fernando da Silva Prado

Fernando J Cardim de Carvalho

Fernando Augusto Mansor de Mattos

Fernando Ferrari Filho

Flávio Tosi Feijó

Flavio Vilela Vieira

Francisco Paulo Cipolla

Gentil Corazza

Gíacomo Balbinotto Neto

Helio Henkin

Jefferson Andronio Ramundo Staduto

João de Deus Sicsú Siqueira

José Carrera Fernandes

Leonardo Monteiro Monasterio

Luís Fernando de Paula

Luis Roberto Nascimento

Manoel Carlos de Castro Pires

Octavio Augusto Camargo Conceição

Patrízia Raggi Abdallah

Robson Antonio Grassi

Ronald Otto Hilbrech

Tiago Wickstrom Alves

Tito Belchior Silva Moreira

Análise Econônica

Ano 23, n ${ }^{\circ} 44$, setembro, 2005 - Porto Alegre

Faculdade de Ciências Economicas, UFRGS, 2000

Periodicidade semestral, março e setembro

1. Teoria Econômica - Desenvolvimento Regional -

Economia Agrícola - Pesquisa Teórica e Aplicada -

Periódicos. I.. Brasil

Faculdade de Ciências Econômicas,

Universidade Federal do Rio Grande do SuI

CDD 330.05

CDU $33(81)(05)$ 


\section{Reestruturação da produção agrícola no Rio Grande do Sul, de 1970 a 1996 e uma estimação para 2012}

Tiago Wickstrom Alves*

Resumo: Esse artigo tem como objetivo detectar as mudanças estruturais ocorridas no Rio Grande do Sul, no que se refere à estrutura agrícola, no período de 1970 a 1996 e projetar as alteraçōes que poderão ocorrer até 2012. Esse estudo foi realizado através do método estrutural-diferencial e do modelo de Edwards, Harniman e Morgan. Por essa abordagem, pôde-se verificar, entre as principais atividades agrícolas, as que foram as mais dinâmicas, no período de 1970 a 1996, o impacto desse dinamismo para o crescimento das regiões e o grau de especialização, de cada região, em cada uma das atividades analisadas. Por fim, foi possível constatar que ocorreu uma significativa melhoria das estruturas produtivas na década de 1970 e após uma concentração espacial do crescimento.

Palavras-chave: Estrutural-diferencial, Modelo de Edwards, Harniman e Morgan, Crescimento regional.

Abstract: The objective of this article is to detect the changes in the agriculture structure occurred in Rio Grande do Sul during the period of 1970 to 1996 and to project possible modifications from 1996 to 2012. This study was carried out using the shift-share method and the Edwards, Harniman e Morgan model. From this standpoint, among the main agricultural activities, during the period of 19701996 , the most dynamic ones were detected. Also, it was determined the impact of this dynamism for the growth of the different regions of the State and the degree of specialization of each one of these regions. It was possible to verify a significant improvement on the productive structures during the 1970's and a spatial concentration of the growth in the following decades.

Keywords: Shift-share, Model of Edwards, Harniman and Morgan, Regional Growth.

JEL Classification: O18, R11, R12.

\section{Introdução}

As teorias que visam explicar o desenvolvimento regional apresentam uma ampla gama de abordagens. A teoria dos Pólos de Crescimento explica o desenvolvimento a partir da existência de urna

* Professor Titular do Curso de Economia da UNISINOS. 
indústria motriz que é capaz de gerar encadeamentos e, em conseqüência disso, torna-se responsável pelo dinamismo da região. Já a teoria da Base Econômica credita o crescimento de uma região ao fato de ela possuir atividades de exportação (setor básico), cujo efeito multiplicador (no sentido keynesiano) se reflete no setor não-básico.

As teorias de Localização Industrial têm como premissa que a indústria é o setor dinâmico e, em vista disso, buscam explicar a localização espacial dessas. Algumas tentam explicar a localização com base no custo mínimo, como o caso do modelo de Weber e Isard. Outras, centram-se na maximização de lucros e na demanda, como, por exemplo o modelo de Lösch.

Teorias mais recentes de localização industrial tomam a seguinte direção: a teoria neoclássica explica a concentração industrial a partir de efeitos externos, ou seja, da abundância de recursos naturais; a Nova Teoria das Trocas Internacionais argumenta que a aglomeração industrial decorre sempre que existir acesso a um amplo mercado, enquanto a Nova Geografia Econômica evidência que a relação existente entre a demanda e custos pode explicar uma estrutura de produção centro-periferia (SURICO, 2003).

Embora exista essa nucleação teórica entre crescimento regional e industrialização, existem outras abordagens que vinculam novos setores ou formas organizacionais como elementos importantes para a promoção do desenvolvimento regional.

No que concerne aos setores, existe atualmente uma concordância entre as pessoas vinculadas à análise regional e ao desenvolvimento econômico, de que a agricultura é um setor-chave no processo do crescimento econômico. Entretanto, a importância que os economistas deram ao papel da agricultura no desenvolvimento econômico, modificou-se muito ao longo do tempo.

Para os fisiocratas, a agricultura era a única atividade que gerava excedente e possibilitava o crescimento. Já, para David Ricardo, à medida que a economia crescia, utilizariam-se terras menos produtivas que reduziriam a renda da terra. Esse processo levaria ao estado estacionário, o qual, no entanto, poderia ser adiado por inovações tecnológicas aplicadas à agricultura, pois ampliariam a produção de alimentos.

Desde o século XIX a meados do século XX, duas correntes dominaram as questões de desenvolvimento: as teorias dos estágios de crescimento e os modelos de economias duais. A dos estágios, enfatizava que uma economia primitiva passaria para a fase pastoril e desta para a agrícola, em que, depois, surgiria o setor manufatureiro e o comércio. A contribuição mais recente para a teoria dos estágios foi 
a de Rostow, em 1971. Já na década de 1930, Fischer e Colin enfatizavam que a mão-de-obra seria transferida do setor primário para o secundário e depois para o terciário, em conseqüência dos avanços tecnológicos que resultariam em diferenças na produtividade de mão-de-obra. A partir desses autores, adota-se, até hoje, a sistemática de dividir a economia em setores primário, secundário e terciário (ACCARINI, 1987, p. 50-51).

Assim, desde o período dos clássicos, até 1950, a maioria dos economistas não considerava a agricultura como um fator importante para o desenvolvimento econômico. Eles apenas analisavam a contribuição da agricultura para o crescimento global, em vez de analisar o processo de crescimento agrícola em si. Ademais, concebiam, em sua maioria, a agricultura como um setor passivo que iria perdendo importância à medida que o setor industrial absorveria a mão-de-obra (EICHER e STAATZ, 1991, p. 47).

$\mathrm{O}$ artigo Economic development with unlimited supplies of labor de Arthur Lewis, escrito em 1954, exerceu grande influência e desencadeou uma série de estudos. Seu modelo explicava que a transferência de mão-de-obra do setor agrícola para o setor capitalista dava-se em função da diferença salarial, e a expansão desse setor ocorreria até que os ganhos nos dois setores se igualassem. Após esse estágio, o crescimento ocorreria conforme o modelo neoclássico de um setor. Ranis e Fei (1961, 1963 e 1964) e Jorgenson (1961) ampliaram o modelo de Lewis, embora continuassem sendo modelos de dois setores que analisavam o processo de transferência de mãode-obra (EICHER e STAATZ, 1991, p. 12-13).

Uma evolução ocorre com o artigo de Johnston e Mellor (1961). Esses autores destacaram outras contribuições do setor agrícola para o desenvolvimento, além de transferência de mão-de-obra, que são: oferta de alimentos para o consumo doméstico, aumento da poupança interna, geração de divisas e expansão do mercado interno para produtos industriais.

Mais recentemente, em um artigo, Timmer (1992, p. 41) acrescenta três importantes contribuições da agricultura para o desenvolvimento.

Primeiro, a existência de beneficios gerados pela agricultura ao crescimento econômico, que extrapolam o mercado e que operam por três mecanismos pouco compreendidos, que são: o impacto da estabilidade dos preços dos alimentos nas decisões de investimentos; a contribuição de crescimento agrícola na produtividade da economia como um todo; e o learnig by doing, por parte dos governantes, que os ajuda a compreenderem o seu papel no pro- 
cesso de desenvolvimento, especialmente mobilizando recursos para investimentos em bens públicos, como infra-estrutura rural.

Segundo, atribui à agricultura um papel especial que é reduzir a pobreza.

Terceiro, ela permitiria proteger o meio ambiente como, por exemplo, manutenção do espaço verde e proteção contra a formação de gases de estufa.

Assim, crê-se que são lícitas as conclusões de Timmer, bem como as de Hayami e Ruttan (1988, p. 47), de que existe atualmente um consenso entre os economistas no sentido de que o crescimento agrícola é fundamental (se não pré-condição) para a industrialização e crescimento global da economia. Ou ainda, como afirma Souza (1997, p. 277), que existe uma forte interdependência entre os setores agrícola e industrial, indicando que a industrialização não se efetua de modo independente da agricultura.

Embora os modelos de análise regional tenham evoluído, ainda carecem de objetividade quando se trata de indicadores de políticas regionais para a promoção do desenvolvimento local. Nesse sentido tem-se migrado para uma abordagem de formação de redes de cooperação dentro de um modo de produção não-fordista e explicitado a importância da construção da cidadania da participação da comunidade na eleição das políticas públicas e na confiança existente entre os agentes envolvidos. Nesse sentido:

Tem-se tornado cada vez mais aceita, nos últimos anos, no Brasil, a idéia de que é necessário criar mecanismos que possibilitem participação mais direta da comunidade na formulação, no detalhamento e na implantação das políticas públicas. A crescente difusão desse enfoque pode ser atribuída, por um lado, ao próprio avanço da democratização do país e, por outro, a uma nova abordagem que vem se tornando dominante no contexto internacional, que enfatiza a importância da participação da sociedade civil e da articulação de atores sociais para as ações relacionadas com a promoção do desenvolvimento (BANDEIRA, 1999, p. 5).

Ou:

... o desenvolvimento local tal como pressupõe uma cidade integradora requer a produção organizada ao longo de todo o território capaz de incluir todos os indivíduos da localidade em um regime de acumulação que combine inovadoramente cooperação e competição [...] o que traz desdobramentos à noção de cidadania e ao papel desempenhado pelos empresários no processo produtivo, os quais são trazidos para dentro do processo de cooperação (COCCO; GALVÃO e SILVA, 1999). 
Embora esse movimento possa sugerir uma indicação de instrumentação para a ação de políticas promotoras do desenvolvimento local, são, na realidade, indicações de um processo necessário para a ação. Gurizatti (1999, p. 95), referindo-se ao processo de industrialização ocorrido no nordeste da Itália, conhecida como Terceira Itália, afirma: “a organização dos sistemas produtivos da Terceira Itália não foi planejada intencionalmente. As instituições locais fecundaram, [...]. Mas ninguém saberia, hoje, reconstruir a seqüência das intervenções para o desenvolvimento dos distritos, nem escrever a receita universal de uma política econômica não fordista."

Essa dificuldade de se ter um modelo teórico que embase não um processo de ação, mas que dê informações mais quantitativas decorrentes da estrutura produtiva de uma região e os possiveis efeitos de uma ação ou da não ação tornam-se extremamente relevantes, pois evidenciam os problemas e dão indicação de onde atuar.

E esse é o sentido deste trabalho. Ou seja, de aplicar um modelo de análise regional que permita evidenciar o que poderia ser o crescimento regional do Rio Grande do Sul, em termos agrícola, até 2012 , tendo em vista a estrutura produtiva apresentada atualmente, dando, assim, informações que auxiliassem na decisão de políticas públicas para a promoção do desenvolvimento regional.

Para uma melhor compreensão dos resultados, procedeu-se a organização deste trabalho da seguinte forma: Na seção seguinte se faz uma apresentação dos procedimentos metodológicos realizados para a elaboração deste trabalho; a seguir tem-se a análise dos resultados. Essa seção está subdividida em duas partes. A primeira trata dos efeitos estruturais ocorridos nos períodos de 1970 a 1980 e de 1980 a 1996. A segunda, aborda o efeito líquido corrido nos períodos analisados e também se faz uma inferência do crescimento para o periodo de 1996 a 2012 . E, por fim, tem-se as conclusões do trabalho.

\section{Procedimentos metodológicos}

Este trabalho utiliza-se do método desenvolvido por Edwards, Harniman e Morgan que teve origem no método proposto por Stilwell. ${ }^{1}$ Esse modelo tem como base a aplicação do método estrutural-diferencial, que é estruturado da seguinte forma:

\footnotetext{
1 Stilwell (1968) parte da equação clássica do método estrutural-diferencial e pondera as diferentes taxas de crescimento do período pelo volume de emprego do final do período, de forma a captar as mudanças estruturais existentes. Entretanto, Chalmers (1971) identificou uma falha existente no método proposto por Stilwell. Porém, não conseguiu corrigir o problema. A
} 
- Variação real do emprego: $\Delta E_{i j}=E_{i j}^{t}-E_{i j}^{o}=E^{o i j}\left(e_{i j}-1\right) \therefore e_{i j}=E_{i j}^{t} / E_{i j}^{o}$

- Variação teórica do emprego: $\Delta_{t} E_{i j}=E_{i j}^{o}(e-1) \therefore e=E^{t} / E^{o}$

- Variação estrutural do emprego: $\Delta_{e} E_{i j}=E_{i j}^{o}\left(e_{i n}-e\right) \therefore e_{i n}=E_{i n}^{t} / E^{o}$

- Variação diferencial do emprego: $\Delta_{d} E_{i j}=E_{i j}^{o}\left(e_{i j}-e_{i n}\right)$

Onde os sobrescritos 0 e $t$ representam o tempo inicial e final respectivamente, e os subscritos $i$, o setor e $j$, a região.

Sendo a equação clássica: $\Delta E_{i j}=\Delta_{i} E_{i j}+\Delta_{e} E_{i j}+\Delta_{d} E_{i j}$

Logo, esse modelo descreve o crescimento líquido $\left(\Delta E_{i j}-\Delta E_{i j}\right)$ como sendo uma função da estrutura produtiva, isto é, se está assentada ou não em indústrias que são dinâmicas em nível nacional (efeito estrutural) e/ou vantagens comparativas em relação às demais (efeito diferencial).

Dos resultados da aplicação desse método, calcula-se o emprego esperado $E\left(E_{i j}^{0}\right)$ no início do período, que é aquele emprego que a região teria no início do período se possuísse a mesma estrutura do final do período, e é encontrado revertendo-se a taxa de crescimento da indústria em nível nacional $\left(\mathrm{e}_{\mathrm{in}}{ }^{-1}\right)$ e aplicando-a no emprego final $\left(E_{i j}^{t}\right)$.

Uma vez calculado o $E\left(E_{i j}^{0}\right)$, então, sobre este, aplicam-se as taxas de crescimento $\boldsymbol{e}$ e $\boldsymbol{e}_{\text {in }}$, e a diferença na extremidade dos vetores (tempo final) seria o valor denominado de MIMS. Este processo de cálculo pode ser visualizado na figura 1 a seguir.

Desta forma, o valor do emprego esperado do setor $i$ da região j é dado por:

$$
E\left(E_{i j}^{0}\right)=E_{i j}^{t}\left(e_{i n}^{-1}\right)
$$

Sendo MIMS dado por:

$$
\text { MIMS }=E_{i j}^{t}-E_{i j}^{t}\left[\left(e_{i n}^{-1}\right)(e)\right]
$$

E o $P M_{i j}$ corrigido, denotado por $P M_{i j}^{c}$, é calculado da seguinte forma:

$$
P M_{i j}^{c}=M I M S-\Delta_{e} E_{i j}
$$

correção foi finalmente obtida por Edwards, Harniman e Morgan (1976), que detectaram onde estava o problema do cálculo proposto por Stilwell e, então, elaboraram uma proposta alternativa, de acordo com o objetivo básico deste último autor. 


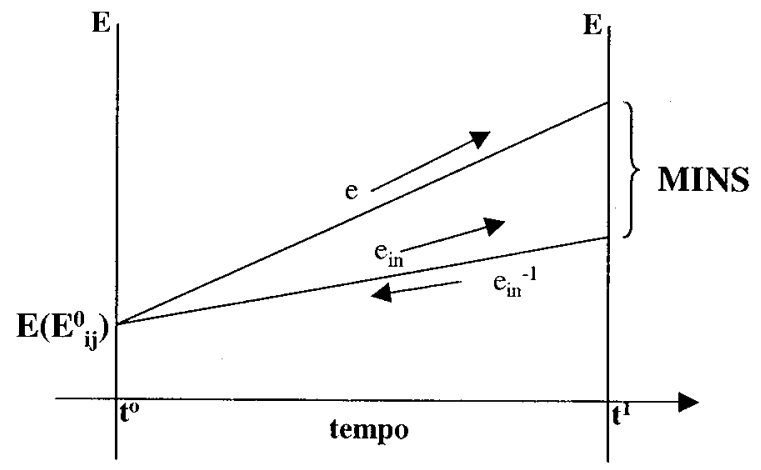

Figura 1: Modelo de Edwards, Harniman e Morgan.

Fonte: autor, com base em Edwards, Harniman e Morgan, 1976.

Com essa contribuição, Edwards, Harniman e Morgan solucionaram de vez o problema da falta de informação quanto às modificações da estrutura produtiva e geraram um modelo eficiente para projetar o crescimento das regióes.

\subsection{Período de análise}

O cálculo do método estrutural diferencial (que serviu de base para o cálculo do método de EDWARDS, HARNIMAN e MORGAN) foi realizado para o período de 1980 a 1996. A partir desses resultados calcularam-se os valores do modelo de Edwards, Harniman e Morgan para detectar as modificações estruturais que ocorreram no último período e para a elaboração da inferência para o período de 1996 a 2012.

Esta divisão busca ajustar os períodos de acordo com as duas principais fases da agricultura. Isto é, de 1970 a 1980, período em que o crédito agrícola foi um fator importante para o desenvolvimento do setor. De 1980 até 1996, quando ocorreram a extinção do crédito subsidiado, o fim do sistema de compras do trigo pelo Banco do Brasil e a implementação de diversos planos econômicos, em que o setor agrícola apresentava-se como atividade-chave para a manutenção dos preços e, finalmente, a abertura da economia e o fortalecimento do Mercosul.

\subsection{Variável utilizada}

A variável utilizada é valor da produção, medida em reais, a preços das safras realizadas entre $1^{\underline{o}}$ de agosto de 1995 a 31 de julho 
de 1996. No efetivo de animais, foi utilizado o preço médio de venda do animal vivo, praticado pelo produtor, em julho de 1996. Assim, as quantidades produzidas nas safras de 1980 e 1996 foram multiplicadas pelos preços praticados no período referido. Dessa forma, as variações, no valor da produção, decorreram apenas das modificações nas quantidades, uma vez que os preços são constantes para todos os períodos. Ou seja, as taxas de crescimento referem-se, exatamente, às taxas de variação da produção, que é o que se está buscando.

Ressalta-se que, no decorrer da apresentação do método, foi utilizado a variável emprego, que era aquela empregada nos modelos e cujos autores trabalharam. Assim, para permitir uma melhor interação das análises e a descrição dos modelos, foi mantida a simbologia daqueles modelos, apesar de a variável ser produção. Logo, a Letra $\mathbf{E}$ estará representando a produção, medida em termos monetários, e não o emprego.

\subsection{Produtos analisados}

Foram analisados 22 produtos que foram selecionados de forma a representarem a expressiva maioria da renda do setor agrícola e, ao mesmo tempo, amplamente produzidos no Estado. Assim, tem-se:

- efetivos e produção de origem animal: bovinos, frangos, ${ }^{2}$ ovinos, suínos, lã, leite e ovos;

- produção de grãos: arroz, aveia, feijão, milho, soja e trigo;

- produção de hortifrutigranjeiros: amendoim, batata-inglesa, cebola, laranja, maçã, mandioca, mel, tomate e uva.

\subsection{Regiões de análise}

No que se refere à divisão territorial, buscou-se analisar as regiões na menor unidade possível. Como os dados de produção não são publicados por distritos, ou seja, a menor unidade de rastreamento da produção é o município, então, essa deveria ser a unidade de estudo. Porém, ocorreram diversas emancipações entre 1970 e 1996 e isso gerou a impossibilidade de reverter a desagregação da produção. Por esse motivo, teve-se que contabilizar aqueles que se emanciparam, no decorrer do período, do município de origem. Note-se que diversos municípios tiveram origem em mais de um, e isso fez com que todos aqueles que estivessem envolvidos na eman-

\footnotetext{
${ }^{2}$ Frangos refere-se ao efetivo de galinhas, galos, frangas, frangos e pintos.
} 
cipação de determinada localidade fossem somados em apenas uma região. Assim, as unidades de análise são, em muitos casos, os municípios e, em outros, um agrupamento desses.

Essas regiōes foram reunidas, numeradas e denominadas, ao longo deste trabalho, por esse número. A codificação e os municípios a que pertence cada região estão especificados no Quadro 1.

\section{Quadro 1: Regiões de análise}

\begin{tabular}{|c|c|c|c|c|c|c|c|}
\hline Código & Municípios & Código & Municípios & Código & Municipios & Código & Municípios \\
\hline 1 & Uruguaiana & 28 & Cerro Branco & 56 & Ibirubá & 72 & Morrinhos do Sul \\
\hline 2 & Itaqui & 28 & Paraíso do Sul & 56 & Quinze de Novembro & 72 & Torres \\
\hline 3 & Garruchos & 29 & Formigueiro & 57 & lvorá & 72 & Três Cachoeiras \\
\hline 3 & Itacurubi & 30 & Restinga Seca & 57 & Júlio de Castilhos & 72 & Três Forquilhas \\
\hline 3 & Jaguari & 31 & Faxinal do Soturno & 57 & Nova Palma & 73 & São Francisco de Paula \\
\hline 3 & Nova Esperança do Sul & 31 & Santa Maria & 57 & Pinhal Grande & 73 & Jaquirama \\
\hline 3 & Santiago & 31 & São Joāo do Polesine & 57 & Quevedos & 74 & Cambará do Sul \\
\hline 3 & Sāo Borja & 31 & Sāo Martinho da Serra & 58 & Alto Alegre & 75 & Bom Jesus \\
\hline 4 & Alegrete & 31 & Silveira Martins & 58 & Campos Borges & 75 & São José dos Ausentes \\
\hline 4 & Manoel Viana & 32 & Sāo Pedro do Sul & 58 & Espumoso & 76 & Campestre da Serra \\
\hline 4 & Säo Francisco de Assis & 33 & São Vicente do Sul & 58 & Salto do Jacuí & 76 & Ipé \\
\hline 5 & Quaraí & 34 & Mata & 59 & Arroio do Tigre & 76 & Vacaria \\
\hline 6 & Santana do Livramento & 35 & Jóia & 59 & Ibirapuitã ( 65 e 132) & 77 & Caxias do Sul \\
\hline 7 & Dom Pedrito & 35 & Tupanciretā & 59 & Lagoāo & 78 & Sāo Marcos \\
\hline 8 & Rosário do Sul & 36 & Dezesseis de Novembro & 59 & Mormaço & 79 & Canela \\
\hline 9 & Cacequi & 36 & Entre-Ijuis & 59 & Segredo & 80 & Gramado \\
\hline 10 & Sāo Gabriel & 36 & Eugênio de Castro & 59 & Soledade & 81 & Riozinho \\
\hline 10 & Săo Sepé & 36 & Pirapó & 59 & Tunas & 81 & Rolante \\
\hline 10 & Vila Nova do Sul & 36 & Santo Ângelo & 60 & Ibarama & 82 & Três Coroas \\
\hline 11 & Lavras do Sul & 36 & São Luiz Gonzaga & 60 & Sobradinho & 83 & Glorinha \\
\hline 12 & Bagé & 36 & Sāo Miguel das Missōes & 61 & Barros Cassal & 83 & Gravataí \\
\hline 12 & Candiota & 36 & Sāo Nicolau & 61 & Boqueirāo do Leão & 84 & Igrejinha \\
\hline 12 & Hulha Negra & 36 & Vitória das Missōes & 61 & Candelária & 85 & Taquara \\
\hline 12 & Pinheiro Machado & 37 & Bossoroca & 61 & Cruzeiro do Sul & 86 & Alvorada \\
\hline 13 & Herval & 38 & Santo Antônio das Missōes & 61 & Gramado Xavier & 87 & Cachoeirinha \\
\hline 14 & Jaguarāo & 39 & Roque Gonzales & 61 & Lajeado & 88 & Esteio \\
\hline 15 & Arroio Grande & 40 & Pedro Xavier & 61 & Mato Leitão & 89 & Sapucaia \\
\hline 16 & Santa Vitória do Palmar & 41 & São Paulo das Missōes & 61 & Progresso & 90 & São Leopoldo \\
\hline 17 & Rio Grande & 42 & Cerro Largo & 61 & Santa Clara do Sul & 91 & Novo Hamburgo \\
\hline 18 & Pedro Osório & 42 & Salvador das Missões & 61 & Santa Cruz do Sul & 92 & Estância Velha \\
\hline 19 & Piratini & 42 & São Pedro do Butiá & 61 & Sério & 93 & Campo Bom \\
\hline 20 & São Lourenço do Sul & 43 & Caibaté & 61 & Simimbu & 94 & Barão \\
\hline 20 & Canguçu & 44 & Guarani das Missōes & 61 & Vale do Sol & 94 & Bom Principio \\
\hline 20 & Cristal $(20 / 27)$ & 45 & Porto Lucena & 61 & Venâncio Aires & 94 & Brochier \\
\hline 21 & Capão do Leāo & 45 & Porto Vera Cruz & 62 & Pantâno Grande & 94 & Carlos Barbosa \\
\hline 21 & Morro Redondo & 45 & Alecrim & 62 & Passo do Sobrado & 94 & Harmonia \\
\hline 21 & Pelotas & 45 & Santo Cristo & 62 & Rio Pardo & 94 & Maratá \\
\hline 22 & São José do Norte & 46 & Novo Machado & 63 & Butiá & 94 & Montenegro \\
\hline 23 & Mostardas & 46. & Porto Mauá & 63 & Minas do Leão & 94 & Porto Novo \\
\hline 23 & Tavares & 46 & Tucunduva & 64 & General Câmara & 94 & Poço das Antas \\
\hline 24 & Cristal $(20 / 27)$ & 46 & Tuparendi & 65 & Triunfo & 94 & Salvador do Sul \\
\hline 24 & Arambaré & 47 & Santa Rosa & 66 & Canoas & 94 & São Pedro da Serra \\
\hline 24 & Baräo de Triunfo & 48 & Cândido Godói & 67 & Portāo & 94 & São Vandelino \\
\hline 24 & Barra do Ribeiro & 49 & Campina das Missōes & 68 & Sāo José do Hortêncio & 94 & Tupandi \\
\hline 24 & Camaquā & 50 & Giruá & 69 & São Sebastiăo do Caí & 95 & Alto Feliz \\
\hline 24 & Cerro Grande do Sul & 51 & Independência & 70 & Capela de Santana & 95 & Feliz \\
\hline 24 & Charqueadas & 52 & Doutor Maurício Cardoso & 71 & Nova Santa Rita & 95 & Linha Nova \\
\hline 24 & Eldorado do Sul & 52 & Horizontina & 67 & Porto Alegre & 95 & Vale Real \\
\hline 24 & Guaiba & 53 & Alegria & 68 & Viamão & 96 & Dois Immäos \\
\hline 24 & Mariana Pimentel & 53 & Catuípe & 69 & Santo Antônio da Patrulha & 96 & lvoti \\
\hline 24 & Sāo Jerônimo & 53 & Chiapeta & 70 & Cidreira & 96 & Lindolfo Collor \\
\hline 24 & Sentinela do Sul & 53 & Inhacorá & 70 & Imbé & 96 & Morro Reuter \\
\hline 24 & Sertāo Santana & 53 & São José do Inhacorá & 70 & Tramandai & 96 & Nova Petrópolis \\
\hline 24 & Tapes & 53 & Três de Maio & 71 & Capão da Canoa & 9 & Picada Café \\
\hline 25 & Amaral Ferrador & 54 & Augusto Pestana & 71 & Maquiné & 96 & Presidente Lucena \\
\hline 25 & Dom Feliciano & 54 & Coronel Barros & 71 & Osório & 96 & Santa Maria do Herval \\
\hline 25 & Encruzilhada do Sul & 54 & Ijuí & 71 & Palmares do Sul & 97 & Sapiranga \\
\hline 26 & Santana da Boa Vista & 55 & Pejuçara & 71 & Terra de Areia & 97 & Nova Hertz \\
\hline 27 & Caçapava do Sul & 56 & Cruz Alta & 71 & Xangrilá & 97 & Parobé \\
\hline 28 & Cachoeira do Sul & 56 & Fortaleza dos Valos & 72 & Arroio do Sal & 98 & Flores da Cunha \\
\hline
\end{tabular}

Fonte: elaborado pelo autor, com base nos dados da pesquisa. 


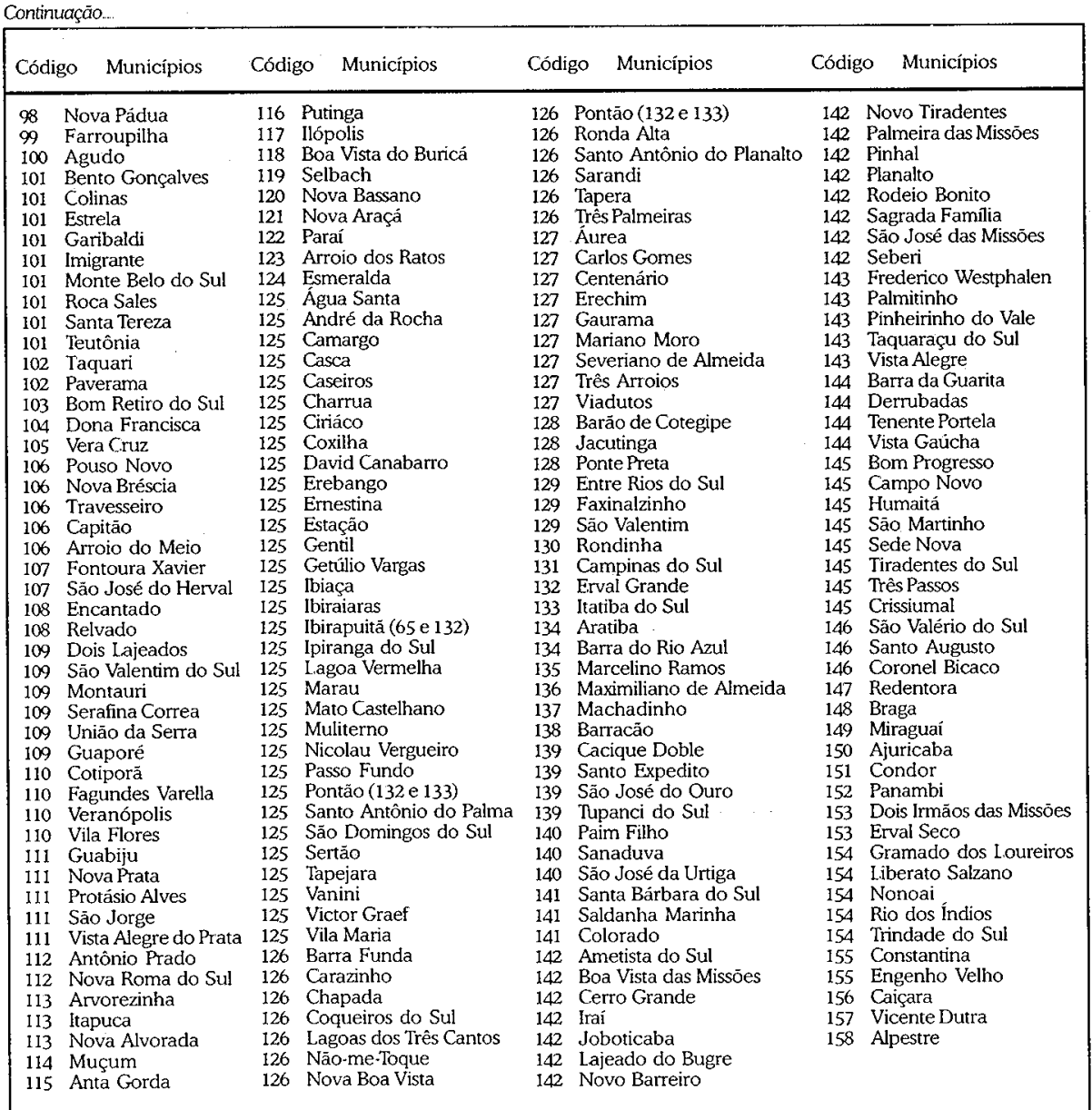

Fonte: elaborado pelo autor, com base nos dados da pesquisa.

Para que se possa ter uma percepção da distribuição espacial dessas regiões, fez-se o mapa apresentado a seguir.

Cabe destacar que cada produto analisado foi considerado como um setor. Desta forma, o trigo representa um setor, a soja outro, e assim sucessivamente. Ainda, a comparação das taxas de crescimento e dos efeitos foi feita somente para esses produtos. Isso significa que, na utilização dos métodos referidos, a produção total do Rio Grande do Sul, em cada período, é a soma total da produção dos produtos selecionados. Desta forma, as inferências e conclusões que foram obtidas referem-se somente a esses e, ainda, nesse Estado. 


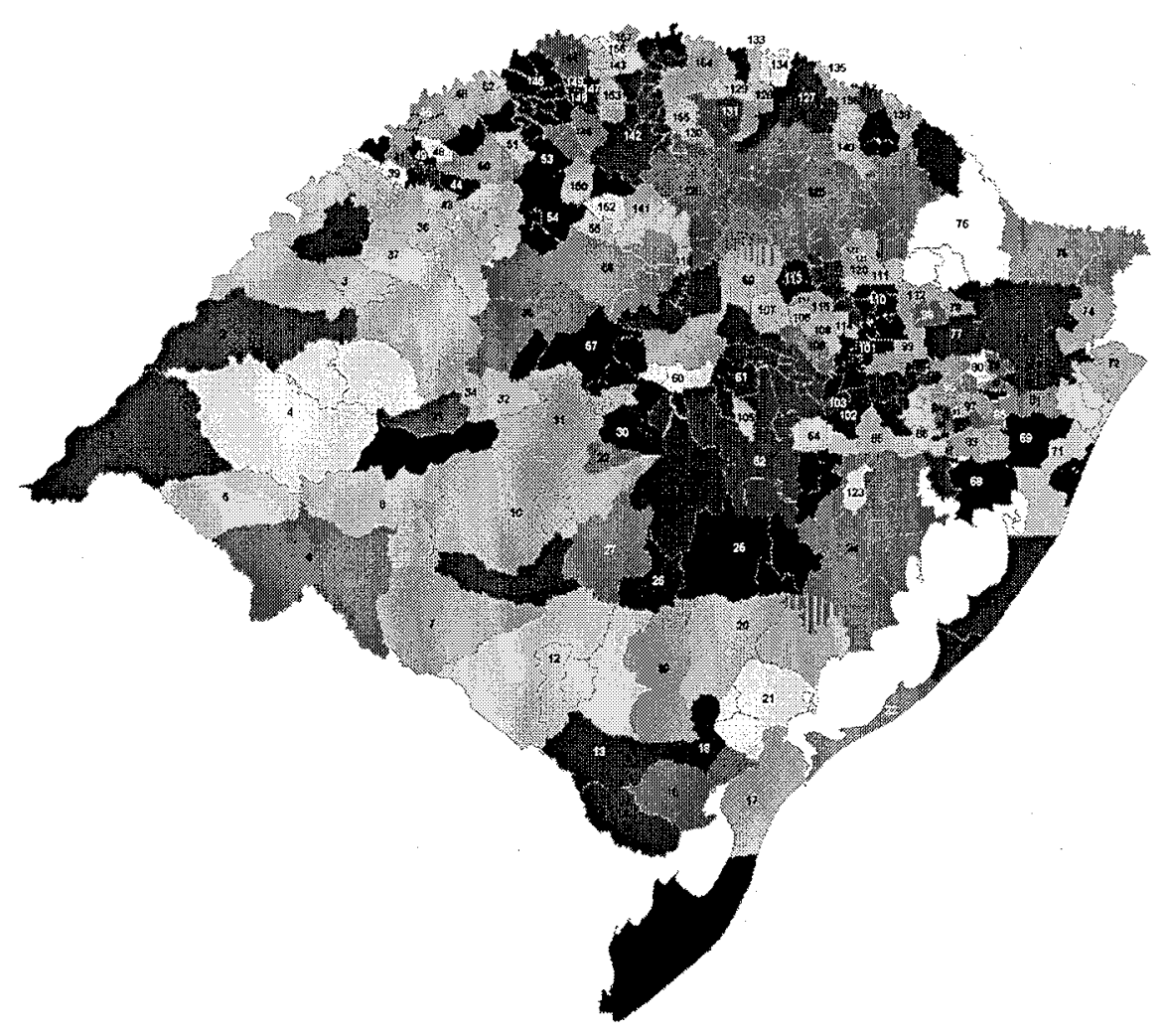

Figura 2: Regiões de análise.

Fonte: elaborado pelo autor, com base nos dados da pesquisa.

\section{Análide dos resultados}

Esta seção analisa comparativamente os efeitos estruturais e lí. quidos que ocorreram nas regiões, nos períodos de 1970 a 1980 e de 1980 a 1996. Contudo, esses efeitos não são abordados para cada região isoladamente, uma vez que o que se busca é evidenciar as conseqüências e as potencialidades que podem decorrer das modificações na estrutura produtiva. Após, é feita a análise das modificações estruturais que ocorreram nas regiões e infere-se, em termos de efeitos líquidos, a respeito do crescimento dessas.

\subsection{Efeitos estruturais dos períodos de 1970 a 1980 e de 1980 a 1996}

Em termos de efeitos estruturais, 54 regiões apresentaram esse efeito positivo e 104 negativo, de 1970 a 1980. Ou seja, no início da 
década de 1970, a expressiva maioria das regiões apresentava especialização em setores não-dinâmicos. Ainda, como a média desse efeito é igual a zero, então, as poucas regiões $\operatorname{com} \Sigma_{i} \Delta_{e} E_{i j}>0$ eram aquelas que possuíam elevada concentração em setores dinâmicos e, ao mesmo tempo, com uma produção relativamente superior às demais nessas atividades.

No período seguinte, 1980-1996, o número de regiões com $\Sigma_{i} \Delta_{e} E_{i j}>0$ passou para 75 e, aquelas com somatório negativo, para 83. Isso significa que de 1970 a 1980 ocorreu uma melhoria na estrutura produtiva das regiões no Estado.

Esse processo de reestruturação, na década de 1970, permitiu que 60 regiões passassem a apresentar uma inversão, de negativo para positivo, no efeito estrutural para o período seguinte. Outras 22 especializaram-se, mas ainda não o suficiente para transformar o $\Sigma_{\mathrm{i}}\left(\Delta_{e} E^{*}{ }_{\mathrm{ij}}+\Delta_{e} E_{\mathrm{ij}}^{\prime}\right)$ em valor maior do que 0 , e 12 , que já haviam apresentado esse efeito positivo, se especializaram ainda mais. Ou seja, 94 regiões apresentaram uma melhoria em suas estruturas produtivas. As que perderam a especialização, apresentaram os seguintes resultados: em 39, a desestruturação foi de tal ordem que resultaram em uma inversão do efeito estrutural de positivo para negativo; 22 , partindo de uma má-estrutura produtiva, pioraram ainda mais; e 3, que estavam assentadas em setores dinâmicos, tiveram uma pequena redução na concentração, de forma que o efeito estrutural diminuiu, mas sem alterar o sinal, que era positivo. Logo, 64 regiões deixaram de ser especializadas.

Dado que o método estrutural-diferencial tem como base o ano inicial do período, então, a estrutura produtiva, que resulta desse modelo, reflete a especialização que a região possuía no ano-base. Sendo assim, a comparação do efeito estrutural apresentado pelas regiões, nos dois períodos de análise, permite verificar as modificações que ocorreram na década de 1970, isto é, ela dá a estrutura existente em 1970 e em 1980. Para analisar as alterações efetuadas entre 1980 e 1996, necessita-se aplicar o modelo de Edwards, Harniman e Morgan.

Logo, o método estrutural-diferencial aplicado para os dois períodos, permitiu verificar a variação estrutural que ocorreu no primeiro e, o de Edwards, Harniman e Morgan, ${ }^{3}$ as modificações no segundo.

3 Lembrando que, para o período de 1980 a 1996, é o valor de MINS que permite verificar se a região se especializou, ou não, em setores dinâmicos. 
Assim, tem-se que, de 1980 a 1996, das 158 regiões, 64 se especializaram, e 94, perderam essa condição. Esses dados são, em termos de número de regióes, o oposto do que ocorreu no período anterior, o que poderia fazer crer que o avanço ocorrido na estrutura da produção do estado, na década de 1970, tivesse sido perdida entre os anos de 1980 a 1996.

Porém, isso não ocorreu. As modificações decorrentes da variação na estrutura produtiva, de 1970 a 1980, fizeram com que 75 regiões apresentassem um efeito estrutural positivo, e 83, negativo. Já aquelas ocorridas no período seguinte, fizeram com que o somatório do MINS, para cada região, resultasse em 64 com valores positivos, e 94 com negativos. Isso significa que aumentou as disparidades regionais no que se refere à dinâmica das regiões em termos de estrutura produtiva, pois poucas cresceram significativamente mais do que a outras tantas. Isso é, como a média desses valores é zero, então, se somente 64 cresceram, significa que o crescimento dessas foi maior do que a queda das demais. Enquanto que, no período de 1970 a 1980, o número de regiões que cresceram foi mais próximo do número de regiōes que decresceram, em termos de efeitos estruturais. Contudo, isso poderia não ser significativo se ocorresse uma redução do desvio-padrão. Porém, nesse caso, o $\sigma$ se ampliou.

Como o s do efeito estrutural se ampliou de 1970 para 1980 e desse para o MINS do período de 1980 a 1996, então pode-se afirmar que as desigualdades regionais estão se ampliando no Estado, no que se refere à especialização das regiões. $\mathrm{E}$, em termos de dinâmica, ocorreu uma melhora entre 1970 e 1980 e uma piora, de 1980 a 1996, entretanto, não a ponto de eliminar totalmente as vantagens obtidas na década de 1970.

Em resumo, durante os anos 1970 os produtores buscaram alterar suas plantas produtivas incorporando setores mais dinâmicos. De 1980 a 1996, ocorre uma desestruturação das regiões, mas de forma menos intensa do que o movimento apresentado entre 1970 e 1980, de forma que a estrutura produtiva das regiões é melhor hoje do que o era em 1970; porém, pior do que a existente no início dos anos 1980, pelo fato de que existem mais regiões com crescimento positivo, atualmente, do que existia em 1970.

Deve-se destacar que essas modificações devem aprofundar intensamente as disparidades regionais para os próximos anos, se não forem implementadas, com urgência, políticas públicas que possibilitem dinamizar as regiões que estão se desestruturando. Essa afirmação decorre do fato de que as regiões que estão se especializando em setores dinâmicos são aquelas que apresentaram dinamismo 
no período anterior, enquanto na década de 1970 esse movimento não foi assim. Essa explicação pode ser mais bem compreendida com a utilização de alguns gráficos. Plotando-se no eixo das abscissas o efeito estrutural do período $t-1$ e, no das ordenadas, o de $t$, obtém-se a figura a seguir.
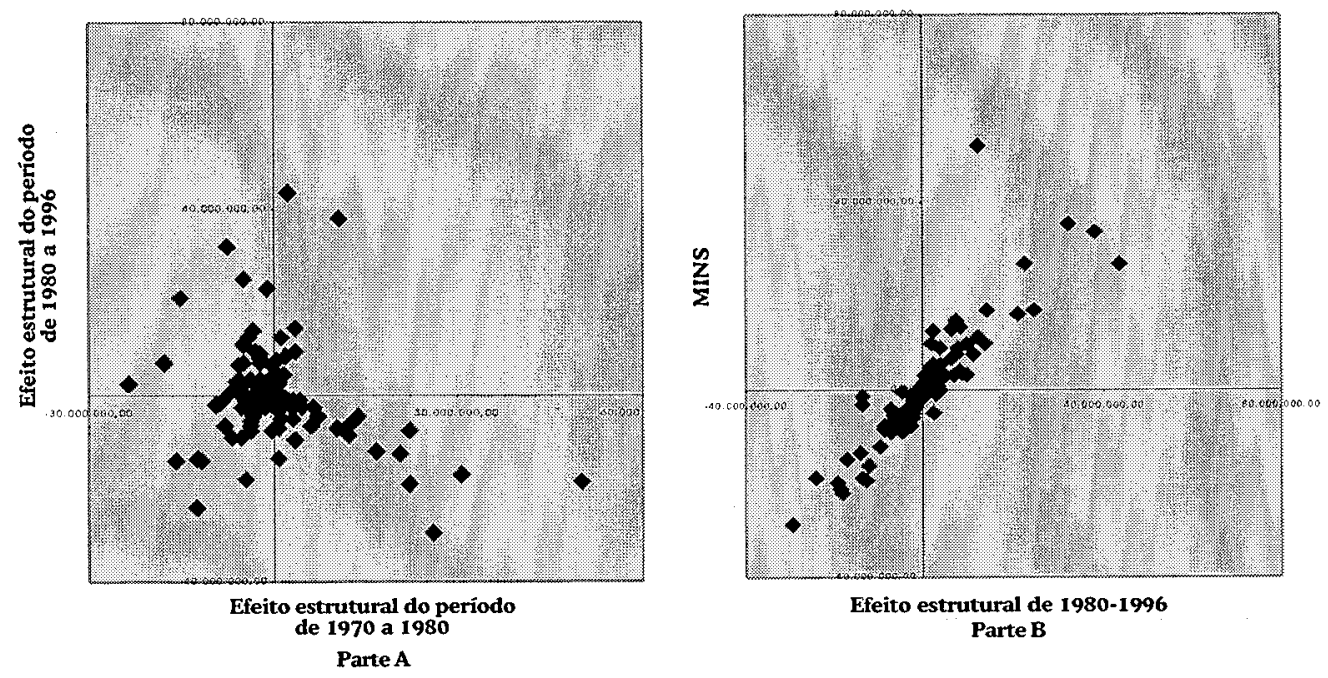

Figura 3: Efeitos estruturais para os períodos de 1970 a 1980, de 1980 a 1996 e o de MINS para 1980 a 1996.

Fonte: elaborado pelo autor, com base nos dados da pesquisa.

Na parte A, da Figura 3, pode-se perceber, nitidamente, que os efeitos das modificações que ocorreram na década de 1970 resultaram em uma distribuição, esse que as regiões se alternaram, em média, no que se refere à especialização em setores dinâmicos. Ou seja, as regiões que haviam crescido em função da estrutura produtiva, em um período, no seguinte, decresceram, sendo que essa relação se inverte na parte B. Isso é realmente preocupante quando se pensa em crescimento harmônico das regiões. Entretanto, deve-se levar em conta o efeito diferencial para avaliar o impacto sobre o efeito líquido. Porém, considerando apenas a estrutura produtiva, essa desigualdade tende a agravar-se intensamente.

Cabe destacar que existe uma forte limitação na capacidade competitiva das regiōes quando se altera a estrutura produtiva. Isso pode se verificar tanto quando se analisa uma região específica e se observa o porquê dos efeitos diferenciais, como quando se analisa a relação existente entre os efeitos estruturais e diferenciais. 
Essa problemática foi encontrada por Alves et al. (1999 a), em Sapucaia do Sul - RS. Nesse município, os produtores alteraram significativamente a estrutura produtiva do município ao longo dos últimos trinta anos, buscando, quase sempre, implementar setores dinâmicos. Contudo, isso não lhes permitia ter competitividade por diversos fatores, entre eles, a falta de experiência na atividade que estava sendo incrementada e a conseqüência foi um efeito líquido negativo.

Em termos de dados globais, isto é, analisando-se estatisticamente (através de uma regressão por mínimos quadrados) a relação existente entre os efeitos estruturais e diferenciais, obtém-se uma influência negativa do efeito estrutural do período $t$ sobre o do efeito diferencial no mesmo período. Contudo, quando essa relação é defasada, isto é, o efeito estrutural em $t$ - 1 sobre o efeito diferencial em $t$, a relação passa a ser positiva.

Resumidamente, fazendo-se: $\Delta d_{t}=\beta_{1} \Delta e_{t}+\beta_{2} \Delta e_{t-1}+e_{i}$

Onde:

$\beta_{i}=$ parâmetros das variáveis

$\Delta d_{t}=$ efeito diferencial do período $\mathrm{t}$

$\Delta e_{\mathrm{t}}=$ efeito estrutural do período $\mathrm{t}$

$\Delta e_{t-1}=$ efeito estrutural do período anterior a $t$

$e_{i}=$ erro aleatório

Obtém-se :

$t$

t signific.

$\mathrm{R}^{2}=0,370$

$$
\Delta d_{t}=-0,708 \Delta e_{t}+0,838 \Delta e_{t-1}+e_{i}
$$

$(0,000)$

$(0,000)$

Esses resultados ajustam-se significativamente à formulação teórica de que: se as regiões estão alterando sua estrutura produtiva, então, é de se esperar que, de início, não apresentem vantagem competitiva, dada a sua inexperiência na atividade, na seqüência, porém, ela terá uma maior competitividade, dado que, ao implementála, seu processo de produção tenderá a seguir o processo tecnológico mais avançado e, ao mesmo tempo, são produtores que estão buscando informações e dispostos a modificar o processo produtivo. Porém, evidentemente, esses elementos não são suficientes para explicar a competitividade das regiões, por isso, o coeficiente de de-' terminação é de apenas 0,370 . 
Como isso impacta os resultados que estavam sendo avaliados? É que, se o efeito diferencial é função positiva do efeito estrutural do período anterior, e se as regiões que estão se especializando são aquelas que já apresentaram esse efeito positivo em períodos anteriores, logo, elas tenderão, coeteris paribus, a crescer a taxas cada vez maiores, enquanto aquelas, com variação estrutural negativa em ambos os períodos, tenderão a perder cada vez mais o seu dinamismo, aprofundando intensamente as diferenças regionais.

Essa relação reporta imediatamente a uma outra questão, que é verificar como se comportou, em média, o efeito líquido para alteraçōes do efeito estrutural. Dadas as relações estabelecidas anteriormente, pode-se inferir a possibilidade de neutralização do efeito líquido para grandes variações do efeito estrutural. Apresentam-se as figuras, a seguir, para verificar esta relação.

A Figura 4 evidencia o fato de que a magnitude e o sinal do efeito estrutural de algumas regiões variaram significativamente. A região 1, por exemplo, não estava centrada em setores dinâmicos, de 1970 a 1980, mas, no período seguinte, de 1980 a 1996, especializouse nesses setores, de forma que seu efeito foi o terceiro em termos de magnitude. Já, na 125, ocorreu o oposto. Outro aspecto interessante é que as regióes situadas entre a 35 e 58 apresentaram elevado efeito estrutural no período de 1970 a 1980 e, no seguinte, um dos menores efeitos. Em contrapartida, o efeito diferencial dessas regiões (em média) foi fortemente negativo na década de 1970, invertendose no período seguinte. Como resultado dessa modificação, o efeito líquido desse grupo esteve próximo de zero, conforme pode ser observado na Figura 5.

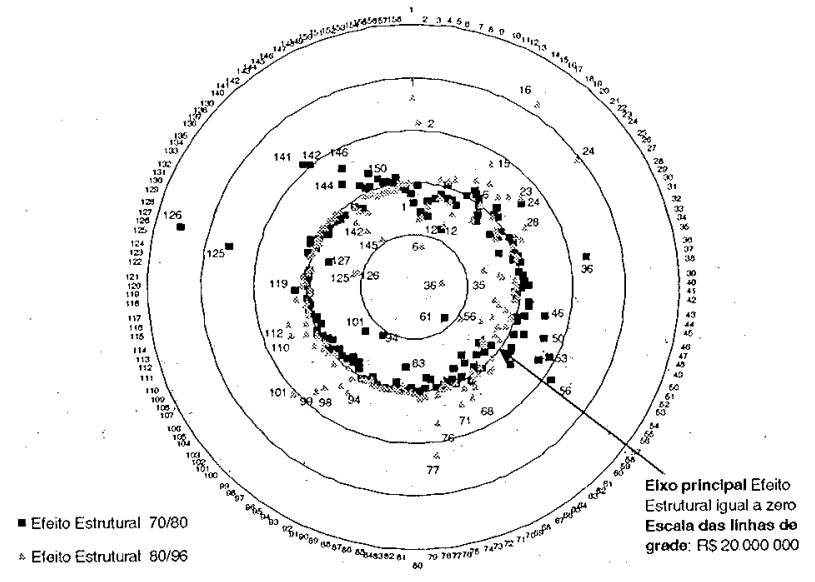

Figura 4: Efeito estrutural das regiões, nos períodos de: 70-80 e de 80-96.

Fonte: elaborado pelo autor, com base nos dados da pesquisa. 


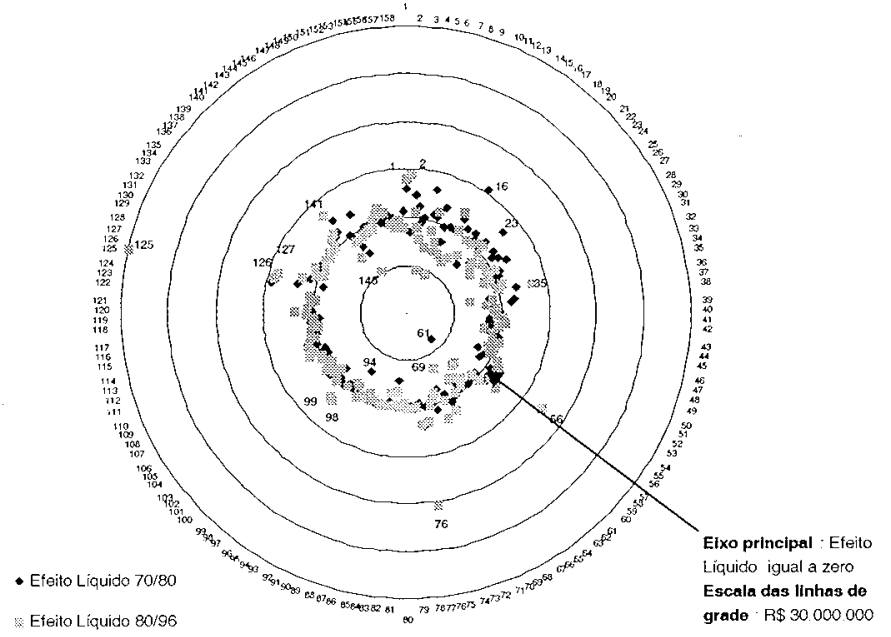

Figura 5: Efeito líquido das regiões, nos períodos de: 70-80 e de 80-98.

Fonte: elaborado pelo autor, com base nos dados da pesquisa.

\subsection{Efeitos líquidos dos períodos de 1970 a 1980, de 1980 a 1996 e inferência de 1996 a 2012}

As regiões que implantaram setores dinâmicos tiveram inicialmente redução do efeito diferencial. Outra relação que surge aqui, e que embora sejam semelhantes nos efeitos, são opostas nos movimentos, é o fato de que as regiões que alteraram sua estrutura produtiva, abandonando atividades dinâmicas em prol daquelas que possuíam vantagens competitivas tiveram como proveito o aumento significativo do efeito diferencial, e com fracasso, a queda intensa do efeito estrutural. $O$ resultado, um efeito líquido próximo de zero.

Esses resultados evidenciam um fator importante para balizar as políticas que visam ao crescimento econômico rural, pois determinadas alterações podem levar a ganhos sob alguns aspectos e perdas em outros, cujo resultado torna-se nulo. Ao mesmo tempo, isso revela um enorme potencial para as políticas de desenvolvimento, pois se as atividades que estiverem sendo substituídas forem aquelas que resultam, por exemplo, em elevados custos ambientais ou que são intensivas em capital, utilizando minimamente a mãode-obra, então, essas modificações podem impactar de forma decisiva a melhoria na qualidade de vida, sem prejuízo econômico. 
Contudo, essa análise foi feita sob as alterações que ocorreram na década de 1970. E, conforme visto na Figura 6, a distribuição do efeito estrutural desse período foi significativamente diferente daquela que se deu entre 1980 e 1996. O fato de as regiões que se especializaram em setores dinâmicos entre 1980 e 1996 terem sido aquelas que possuíam uma base em que a estrutura existente permitiu um efeito líquido positivo, então, nesse intervalo de tempo, o efeito estrutural não deve exercer influência negativa no efeito diferencial. Existem duas razões para isso.

A primeira é o fato de que uma parcela do valor de MINS decorre do aumento na concentração em produtos dinâmicos. Sendo assim, não está se implementando novas atividades, mas, sim, incrementando aquelas dinâmicas, já existentes.

Segunda, como existe uma relação positiva entre o efeito estrutural do período $t-1$ para o efeito diferencial de $t$, e como essas regiões, em sua maioria, ampliaram a concentração nas atividades já existentes, então, é possível que o efeito estrutural de $t$ passe a exercer uma influência positiva no efeito diferencial em $t$. Ou seja, resumidamente, poderia-se, teoricamente, supor que: $\Delta d_{t}=f\left(\Delta e_{t}, \Delta e_{t-1}, \Phi\right)$ onde: $\delta \Delta d_{t} / \delta \Delta e_{t}>0, \delta \Delta d_{t} / \delta \Delta e_{t-1}>0$ e $\Phi$ é uma função de outras variáveis que contribuem para explicar $\Delta d_{t}$.

No que se refere ao efeito líquido, ele é uma função do efeito diferencial e estrutural, isso é: $\Delta \boldsymbol{l}_{t}=\Gamma\left(\Delta e_{t}, \Delta d_{t}\right)$. E, dada a suposição anterior, então, ela poderia ser rescrita como sendo: $\Delta \boldsymbol{I}_{t}=\Gamma\left(\Delta e_{t}, \Delta e_{t-1}, \Phi\right)$ onde: $\delta \Delta \boldsymbol{l}_{t} / \delta \Delta e_{t}>0, \delta \Delta \boldsymbol{l}_{t} / \delta \Delta e_{t-1}>0$.

Abstraindo-se as relações descritas acima, em relação a função f, e supondo que $\delta \Delta d_{t} / \delta t=\delta \Delta d_{t+1} / \delta t$ e que a dinâmica dos setores permaneça constante, então, pode-se avaliar como será o crescimento das regiões decorrente das alterações nas estruturas produtivas realizadas nos últimos anos.

Plotando os valores do efeito líquido do período $t$ no eixo das ordenadas, e o que ocorreu no período anterior, no eixo das abscissas, pode-se comparar a dinâmica de crescimento das regiões. Assim, calculando o efeito líquido para o período de 1996 a 2012, dada a suposição acima, e tomando os efeitos dos período de 1970 a 1980 e de 1980 a 1996, tem-se a Figura 6, a seguir. 


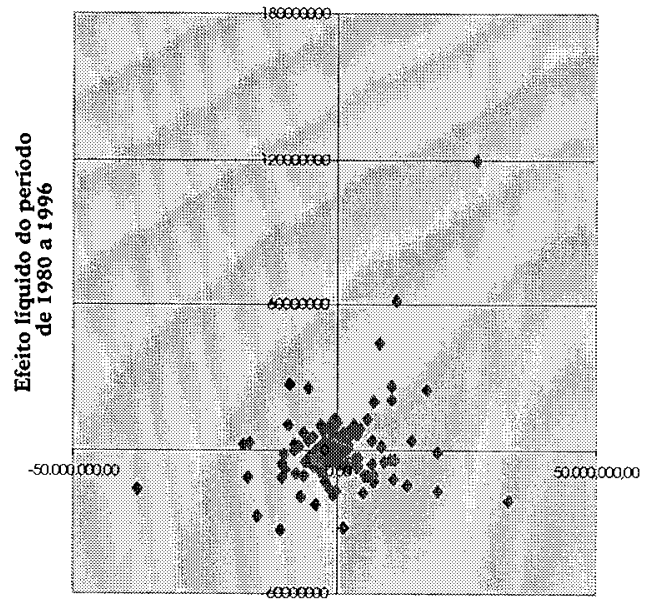

Efeito líquido do periodo de 1970 a 1980
Efeito liquido do periodo de 1970 a 1980

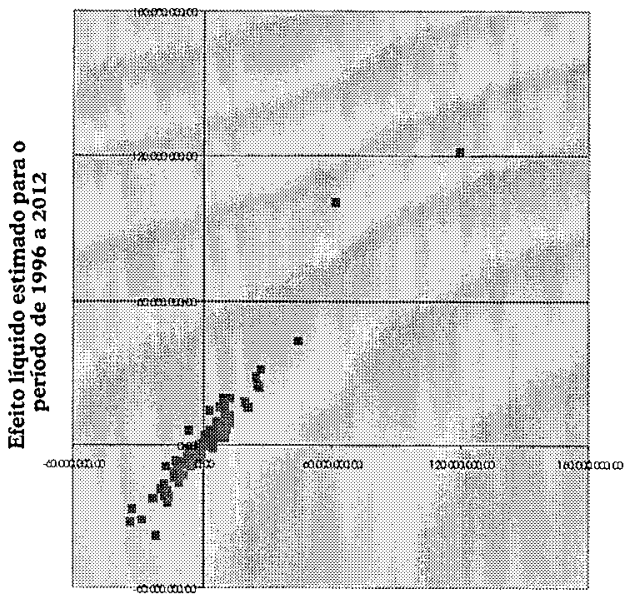

Efeito líquido do periodo de 1980 a 1996 Parte B

Figura 6: Efeitos líquidos para os períodos de 1970 a 1980, de 1980 a 1996 e o estimado para o período de 1996 a 2012.

Fonte: elaborado pelo autor, com base nos dados da pesquisa.

$\mathrm{O}$ quadro, a seguir, permite verificar quais as regiões que apresentaram efeito líquido positivo ou negativo em cada período e, ao mesmo tempo, sua perspectiva de crescimento para o período de 1996 a 2012.

Pelo Quadro 2, pode-se observar que o número de regiōes com efeito líquido positivo vem diminuindo a cada período. Como a média desse efeito é sempre zero, então, esse é outro argumento que evidencia o processo de concentração econômica no Rio Grande do Sul.

Somente 31 regiões apresentaram efeito positivo nos dois períodos e mostrarão esse mesmo sinal nos próximos anos, sendo que 61 regiões resultaram em um efeito negativo para os três períodos. $\mathrm{O}$ Quadro 3 permite identificar essas regiões.

As figuras anteriores permitem verificar que as regióes que apresentaram efeito líquido positivo entre 1980 e 1996 serão, em média, as que mais irão crescer nos próximos 16 anos. $E$ isso decorre da influência do efeito estrutural sobre o efeito líquido e da dinâmica do processo de crescimento dos últimos anos, que deu-se de forma distinta da que ocorreu nos anos 1970, conforme visto no início deste capítulo. Nessa década ocorreu uma compensação entre crescimento em um período e crescimento negativo no período seguinte. Porém, essa oscilação, mantida a suposição anterior, não irá ocorrer nos próximos anos. 
Quadro 2: Sinal do efeito líquido das regióes para os períodos de: 1970 a 1980, 1980 a 1996, e o previsto para 1996 a 2012

\begin{tabular}{|c|c|c|c|c|c|c|c|c|c|c|}
\hline Sinal do efeito líquido & \multicolumn{9}{|c|}{ Regiōes } & Total de Regiōes \\
\hline \multirow{8}{*}{$\begin{array}{l}\text { Regiōes que apresenta- } \\
\text { ram efeito liquido positivo } \\
\text { de } 1970 \text { a } 1980\end{array}$} & 1 & 3 & 4 & 6 & 7 & 8 & 9 & 10 & 15 & \multirow{8}{*}{68} \\
\hline & 16 & 17 & 19 & 20 & 22 & 23 & 25 & 26 & 27 & \\
\hline & 28 & 29 & 30 & 31 & 33 & 35 & 37 & 38 & 55 & \\
\hline & 56 & 57 & 58 & 67 & 68 & 72 & 76 & 78 & 91 & \\
\hline & I 03 & 112 & 113 & 116 & 117 & 120 & 121 & 122 & 123 & \\
\hline & 124 & 125 & 126 & 128 & 129 & 130 & 131 & 132 & 134 & \\
\hline & 136 & 137 & 139 & 140 & 141 & 142 & 146 & 147 & 148 & \\
\hline & 150 & 151 & 154 & 155 & 158 & & & & & \\
\hline \multirow{10}{*}{$\begin{array}{l}\text { Regiōes que apresenta- } \\
\text { ram efeito líquido } \\
\text { negativo de } 1970 \text { a } 1980\end{array}$} & 2 & 5 & 11 & 12 & 13 & 14 & 18 & 21 & 24 & \multirow{10}{*}{90} \\
\hline & 32 & 34 & 36 & 39 & 40 & 41 & 42 & 43 & 44 & \\
\hline & 45 & 46 & 47 & 48 & 49 & 50 & 51 & 52 & 53 & \\
\hline & 54 & 59 & 60 & 61 & 62 & 63 & 64 & 65 & 66 & \\
\hline & 69 & 70 & 71 & 73 & 74 & 75 & 77 & 79 & 80 & \\
\hline & 81 & 82 & 83 & 84 & 85 & 86 & 87 & 88 & 89 & \\
\hline & 90 & 92 & 93 & 94 & 95 & 96 & 97 & 98 & 99 & \\
\hline & 100 & 101 & 102 & 104 & 105 & 106 & 107 & 108 & 109 & \\
\hline & 110 & $1 I I$ & 114 & I I 5 & 118 & 119 & 127 & 133 & 135 & \\
\hline & 138 & 143 & 144 & 145 & 149 & 152 & 153 & 156 & 157 & \\
\hline \multirow{8}{*}{$\begin{array}{l}\text { Regiōes que apresenta- } \\
\text { ram efeito liquido positivo } \\
\text { de } 1980 \text { a } 1996\end{array}$} & I & 2 & 3 & 9 & 14 & I 5 & 20 & 21 & 22 & \multirow{8}{*}{61} \\
\hline & 29 & 33 & 35 & 42 & 43 & 48 & 53 & 54 & 55 & \\
\hline & 56 & 57 & 58 & 59 & 68 & 71 & 75 & 76 & 77 & \\
\hline & 94 & 98 & 99 & 100 & 104 & 107 & 109 & 110 & 111 & \\
\hline & 112 & 114 & 115 & 119 & 120 & 121 & 122 & 124 & 125 & \\
\hline & 124 & 125 & 126 & 128 & 129 & 130 & 131 & 132 & 134 & \\
\hline & 126 & 127 & 128 & 129 & 131 & I 34 & 136 & 137 & 138 & \\
\hline & 139 & 140 & 141 & 150 & 151 & 152 & 153 & & & \\
\hline \multirow{11}{*}{$\begin{array}{l}\text { Regiöes que apresenta- } \\
\text { ram efeito líquido } \\
\text { negativo de } 1980 \text { a } 1996\end{array}$} & 4 & 5 & 6 & 7 & 8 & 10 & I 1 & 12 & 13 & \multirow{11}{*}{97} \\
\hline & 16 & 17 & 18 & 19 & 23 & 24 & 25 & 26 & 27 & \\
\hline & 28 & 30 & 31 & 32 & 34 & 36 & 37 & 38 & 39 & \\
\hline & 40 & 41 & 44 & 45 & 46 & 47 & 49 & 50 & SI & \\
\hline & 52 & 60 & 61 & 62 & 63 & 64 & 65 & 66 & 67 & \\
\hline & 69 & 70 & 72 & 73 & 74 & 78 & 79 & 80 & 81 & \\
\hline & 82 & 83 & 84 & 85 & 86 & 87 & 88 & 89 & 90 & \\
\hline & 91 & 92 & 93 & 95 & $96^{\circ}$ & 97 & 101 & 102 & 103 & \\
\hline & 105 & 106 & 108 & 113 & 116 & 117 & 118 & 123 & 130 & \\
\hline & 132 & 133 & 135 & 142 & 143 & 144 & 145 & 146 & 147 & \\
\hline & 148 & 149 & 154 & 155 & 156 & 157 & 158 & & & \\
\hline \multirow{7}{*}{$\begin{array}{l}\text { Regiöes que deverão } \\
\text { apresentar efeito liquido } \\
\text { positivo de } 1996 \text { a } 2012\end{array}$} & I & 2 & 3 & 4 & 9 & 14 & 15 & 20 & 21 & \multirow{7}{*}{59} \\
\hline & 22 & 29 & 33 & 35 & 43 & 54 & 55 & 56 & 57 & \\
\hline & 58 & 59 & 68 & 71 & 75 & 76 & 77 & 94 & 98 & \\
\hline & 99 & 100 & 103 & 104 & 107 & 108 & 109 & 111 & 113 & \\
\hline & I I 4 & 115 & 119 & 120 & 121 & 124 & 125 & 126 & 127 & \\
\hline & I 28 & 129 & $13 I$ & 134 & 136 & 137 & 138 & 139 & 140 & \\
\hline & 141 & 150 & 151 & 152 & 153 & & & & & \\
\hline \multirow{9}{*}{$\begin{array}{c}\text { Regiōes que deveräo } \\
\text { apresentar efeito líquido } \\
\text { negativo de } 1996 \text { a } 2012\end{array}$} & 5 & 7 & 13 & 16 & 17 & 18 & 19 & 23 & 24 & \multirow{9}{*}{99} \\
\hline & 25 & 27 & 34 & 36 & 37 & 38 & 39 & 40 & 41 & \\
\hline & 42 & 45 & 50 & 51 & 52 & 53 & 60 & 61 & 62 & \\
\hline & 63 & 65 & 72 & 73 & 74 & 78 & 79 & 80 & 81 & \\
\hline & 82 & 84 & 89 & 90 & 91 & 92 & 93 & 95 & 96 & \\
\hline & 97 & 102 & 116 & 117 & 118 & 122 & 123 & 130 & 132 & \\
\hline & 100 & 101 & 102 & 104 & 105 & 106 & 107 & 108 & 109 & \\
\hline & 133 & 142 & 147 & 148 & 149 & 154 & 155 & 156 & 157 & \\
\hline & 158 & & & & & & & & & \\
\hline
\end{tabular}

Fonte: elaborado pelo autor, com base nos dados da pesquisa. 
Quadro 3: Regiões com mesmo sinal do efeito líquido nos três períodos

\begin{tabular}{|c|c|c|c|c|c|c|c|c|c|c|c|c|}
\hline Sinal do efeito líquido & \multicolumn{11}{|c|}{ Regiões } & Total de Regiōes \\
\hline $\begin{array}{l}\text { Regióes com efeito positi- } \\
\text { vo nos períodos de } 1970 \text { a } \\
1980,1980 \text { a } 1996 \text { e pre- } \\
\text { visto para } 1996 \text { a } 2012\end{array}$ & $\begin{array}{l}1 \\
57 \\
131\end{array}$ & $\begin{array}{l}3 \\
58 \\
134\end{array}$ & $\begin{array}{l}9 \\
68 \\
136\end{array}$ & $\begin{array}{l}15 \\
76 \\
137\end{array}$ & $\begin{array}{l}20 \\
120 \\
139\end{array}$ & $\begin{array}{l}22 \\
\mathrm{I} 21 \\
\mathrm{I} 40\end{array}$ & $\begin{array}{l}29 \\
124 \\
141\end{array}$ & $\begin{array}{l}33 \\
125 \\
150\end{array}$ & $\begin{array}{l}35 \\
126 \\
151\end{array}$ & $\begin{array}{l}55 \\
128\end{array}$ & $\begin{array}{r}56 \\
129 \\
\end{array}$ & 31 \\
\hline $\begin{array}{l}\text { Regiôes com efeito nega- } \\
\text { tivo nos períodos de } 1970 \\
\text { a } 1980,1980 \text { a } 1996 \text { e pre- } \\
\text { visto para } 1996 \text { a } 2012\end{array}$ & $\begin{array}{l}5 \\
41 \\
62 \\
81 \\
93 \\
143\end{array}$ & $\begin{array}{l}11 \\
44 \\
63 \\
82 \\
95 \\
144\end{array}$ & $\begin{array}{l}12 \\
45 \\
64 \\
83 \\
96 \\
145\end{array}$ & $\begin{array}{l}13 \\
46 \\
65 \\
84 \\
97 \\
149\end{array}$ & $\begin{array}{l}18 \\
47 \\
66 \\
85 \\
101 \\
156\end{array}$ & $\begin{array}{l}24 \\
49 \\
69 \\
86 \\
102 \\
157\end{array}$ & $\begin{array}{l}32 \\
50 \\
70 \\
87 \\
105\end{array}$ & $\begin{array}{l}34 \\
51 \\
73 \\
88 \\
106\end{array}$ & $\begin{array}{l}36 \\
52 \\
74 \\
89 \\
118\end{array}$ & $\begin{array}{l}39 \\
60 \\
79 \\
90 \\
133\end{array}$ & $\begin{array}{r}40 \\
61 \\
80 \\
92 \\
135\end{array}$ & 61 \\
\hline
\end{tabular}

Fonte: elaborado pelo autor, com base nos dados da pesquisa.

Os dados do Quadro 2 são ainda mais reveladores do efeito perverso da dinâmica de crescimento do Rio Grande do Sul, pois o número de regiōes que têm crescido menos que a média do Estado é quase o dobro do que o daquelas com crescimento acima da média. E isso, por mais de 40 anos. Pode-se imaginar as disparidades regionais que esse Estado terá, se não surgirem alternativas para esse processo.

\section{Conclusões}

Este estudo permitiu verificar que na década de 1970 ocorreu uma melhoria significativa na estrutura produtiva do Rio Grande do Sul que permitiu um forte incremento da produção agrícola e que, no período seguinte, houve uma desestruturação da produção.

Ainda, pôde-se verificar que parte do efeito diferencial é dependente do efeito estrutural,. Ou seja, as vantagens competitivas dependem, em parte, das alterações estruturais que ocorrem nas regiões

Por fim, a análise evidenciou que a projeção da dinâmica de crescimento da agricultura, vista através do efeito líquido das regiões, gera um processo excludente. Isso é, regiões mais ricas crescerão a taxas mais elevadas, enquanto as mais pobres terão crescimento líquido negativo. Sendo assim, pode-se afirmar que o Rio Grande do Sul necessita de uma política de desenvolvimento regional que tente minimizar esse crescimento desigual mas que, ao mesmo tempo, não impeça o crescimento global. 
Cabe destacar que essas conclusões foram obtidas sob as hipóteses de que a dinâmica dos setores e a competitividade das regiōes mantenham-se constantes. Evidentemente, isso é muito difícil de ocorrer, logo poderia se supor que esses resultados são totalmente descolados da realidade. Contudo, se não houver alterações na política agrícola que alterem a competitividade das regiões, dada a relação dessa com o efeito estrutural e as modificações que ocorreram nas duas últimas décadas, então, é razoável esperar que essas estimativas estejam aquém do que irá ocorrer. Isto é, se as relações entre o efeito diferencial e o estrutural forem como os descritos na função f, então, o agravamento nas disparidades regionais será, ainda, maior do que o projetado.

Contudo, cabe destacar que essas estimativas não estão levando em consideração o esgotamento dos recursos. Assim, pode ocorrer que determinadas regiões tenham atingido seu limite, em termos de recursos naturais, para exploração das atividades que possuem competitividade, de forma que terão que alterar sua estrutura produtiva para evitar a queda de sua taxa de crescimento, que pode, inclusive, estancar seu dinamismo.

Algo que pode alterar, de forma mais significativa, esses resultados são as modificações na dinâmica dos setores. E isso depende do mercado e de políticas agrícolas, logo, não existe possibilidade, a médio prazo, de as regiões, de forma independente, gerarem uma dinâmica que permita reduzir as desigualdades. Para tal, tanto o Estado como a União terão de unir esforços no sentido de estabelecer políticas agrícolas que revitalizem as regióes com menor dinamismo $\mathrm{e}$, ao mesmo tempo, que não desestimulem aquelas com elevada competitividade.

No que se refere às políticas em nível estadual, crê-se que elas devam, entre outras possibilidades, ser direcionadas a modificar a especialização das regiões. Isto é, dada as atividades dinâmicas e a competitividade de cada região, deve-se estabelecer mecanismos que possibilitem alterar suas estruturas de forma que cada região possa maximizar suas potencialidades, tendo em vista o dinamismo das atividades.

\section{Referências bibliográficas}

ACCARINI, José Honório. Economia rural e desenvolvimento: reflexões sobre o caso brasileiro. Petrópolis, Vozes, 1987.

ALBUQUERQUE, Roberto Cavalcanti de 3 CAVALCANTI, Clóvis de Vasconcelos. Desenvolvimento regional no Brasil. Brasilia, IPEA, 1976. 
ALONSO. José Antônio Fialho. Evolução das desigualdades inter-regionais de renda interna no Rio Grande do Sul 1939-1970. Porto Alegre, FEE, 1986.

ALONSO. José Antônio Fialho 63 BANDEIRA, Pedro Silveira. Crescimento inter-regional no Rio Grande do Sul nos anos 80. In: A Economia Gaúcha e os anos 80. Porto Alegre, FEE, 1990. Tomo 1, p. 67-130.

ALONSO. José Antônio Fialho; BENETTI, Maria Domingues E BANDEIRA, Pedro Silveira. Crescimento econômico da região sul do Rio Grande do Sul: causas e perspectivas. Porto Alegre, FEE, 1994.

ALVES, Tiago Wickstrom et al. Diagnóstico socioeconômico do município de Sapucaia do Sul. Porto Alegre, SEBRAE, 1999 a. $1999 \mathrm{~b}$

Diagnóstico socioeconômico do município de Dois Irmãos. Porto Alegre, SEBRAE,

ANDRIKOPOULOS, A; BROX J. E CARVALHO E. Shift-Share Analysis and the Potential for Predicting Regional Growth Patterns: Some Evidence for the Region of Quebec, Canada. Growth and Change. v. 21, n. 1, p. 1-10, Winter, 1990.

ASHBY, Lowell D. Changes in regional industrial structure: a comment. Urban Studies, v. 7, p. 298-304, 1970.

BANDEIRA, Pedro. Participação, articulação de atores sociais e desenvolvimento regional. Brasilia, IPEA, Texto para Discussão n. 630, fevereiro, 1999.

BARBOSA, Joaquim Eduardo W. E GIL, Sergio Murilo P. Divisão territorial do Rio Grande do Sul. Porto Alegre, IBGE - Setor de Documentação e Disseminação de Informações, 1997.

BEAUDRY, Richard $\mathcal{E}$ MARTIN, Fernand. Shift-Share Analysis Revisited: The allocatio-n effect and the stability of regional structure, a comment. Journal of Regional Science, v. 19, n. 3, p. 389-391, 1979.

BROWN, H. James. Shift and share projections of regional economic growth: an empirical test. Journal of Regional Science, v. 9, n. 1, p. 1-17, 1969.

CARVALHO, João Carlos M. O desenvolvimento da agropecuária brasileira: da agricultura escravista ao sistema agroindustrial. Brasília, Ed. Agropecuária, 1992.

CHALMERS, James A. Measuring changes in regional industrial structure: a comment on Stilwell and Ashby. Urban Studies, v. 8, n. 3, p.289-292, oct. 1971.

COCCO; Giuseppe; URANI, André e GALVÄO. Alexandre P. Desenvolvimento local e espaço público na Terceira Itália: questões para a realidade brasileira. In: Empresáriose empregos nos novos territórios produtivos: o caso da Terceira Itália. Org. COCCO; Giuseppe; URANI, André e GALVÃO. Alexandre P. Rio de janeiro, DPEA, 1999.

EDWARDS, J. Arwel; HARNIMAN, K. F. \&3 MORGAN, J.S. Regional growth and structural adaptation: a correction to the Stilwell modification. Urban Studies, v. 15, n. 1, p. 97-100, feb. 1978.

EICHER, Carl K $\mathcal{G}$ STAATZ, John M (orgs). Desarrollo agrícola en el Tercer Mundo. México, Fondo de Cultura Económica, 1991.

ESTEBAN-MARQUILLAS, J. M. A reinterpretation of shift-share analysis. Regional and Urban Economics, v. 2, n. 3, p. 249-255, 1972.

FEE - Fundação de Economia e Estatística Siegfried Emanuel Heuser. Programa Agroindústria Rio Grande do Sul: indústria de leite e derivados. Porto Alegre, 1978. Tomo 1, v. 14.

25 anos da economia gaúcha. A agricultura no Rio Grande do Sul. 2 ed. Porto Alegre, 1979. v. 3 e Anexo. 
FEE - Fundação de Economia e Estatística Siegfried Emanuel Heuser. Duas décadas da produção e do produto da agropecuária do RS: 1964-84. Porto Alegre, 1986. Tomos 1 e 3. $\overline{1989}$.

. Municípios do Rio Grande do Sul: dados socioeconômicos 1985-87. Porto Alegre,

Produto Interno Bruto Municipal. Porto Alegre, 1999.

GRANDO. Marinês Zandavali (org.). Agropecuária do Rio Grande do Sul: 1980-1995 o caminho da eficiência? Porto Alegre, FEE, 1996.

GURIZATTI, Paolo. O nordeste italiano: nascimento de um novo modelo de organização industrial. In: Empresários e empregos nos novos territórios produtivos: o caso da Terceira Itália. Org. COCCO; Giuseppe; URANI, André e GALVÃO. Alexandre P. Rio de janeiro, DP\&A, 1999.

HAYAMI, Yujiro \&3 RUTTAN, Vermon W. Desenvolvimento agrícola: Teorias e experiências internacionais. Brasilia, Empresa Brasileira de Pesquisas Agropecuárias - EMBRAPA, 1988.

HAYNES, Kingsley $\mathcal{B}$ MACHUNDA, Zachary B. Considerations in extending shift-share analysis: note. Growth and Change. v. 18, n. 2, p. 69-78, Spring, 1987.

HERZOG, Henry W. $\mathcal{O}$ OLSEN, Richard J. Shift-Share Analysis Revisited: the allocation effect and the stability of regional structure. Journal of Regional Science, v. 17, n. 3, p. 441454, 1977.

Shift-Share Analysis Revisited: the allocation effect and the stability of regional structure, a reply. Journal of Regional Science, v. 19, n. 3, p. 393-395, 1979.

HOLDEN, Darryl R.; NAIRN, Alisdaire G. M. 8 SWALES, J. K. Shift-share analysis of regional growth and policy: a critique. Oxford Bulletin of Economics and Statistics, V. 51 , n. 1, p. 15-34, Feb., 1989.

IBGE - Fundação Instituto Brasileiro de Geografia e Estatística. Enciclopédia dos municípios. Rio de Janeiro, 1959. v. XXXIII.

IBGE - Fundação Instituto Brasileiro de Geografia e Estatística. Censo agropecuário. Rio Grande do Sul. VIII Recenseamento geral do Brasil - 1970. Rio de Janeiro, 1974. v. III, tomo XXI.

Censo agropecuário. Rio Grande do Sul. IX Recenseamento geral do Brasil-1980. Rio de Janeiro, 1984. v. 2, tomo 3, $1^{\text {a }}$ e $2^{\mathrm{a}}$ partes.

. Anuário estatístico 1996. Rio de Janeiro, 1997.

Dados gerais do Brasil. www.ibge.gov.br, jan., 1998 b.

Municípios criados e alterações toponímicas municipais verificadas a partir de 01/07/

1983. Centro de Documentação e Disseminação de Informações. Departamento de Atendimento Integrado. Rio de Janeiro, 1998 c.

KEIL, Stanley R. On the value of homotheticity in the shif-share framework. Growth $\mathbb{E}$ Change, v. 23, p. 469-493, FALL 1992.

KLOSTERMAN, Richard E. Community analysis and planning techniques. Maryland: Rowman 8 Littlefield, 1990. Chapter 12. Constant-share and shift-share approaches, p. 169-187.

LEDEBUR, Larry C. $\&$ MOOMAW, Ronald L. Shift-Share analysis of regional Labor productivity in manufacturing. Growth and Change, v. 14, n. 1, p. 2-9, jan. 1983.

NCDOUNOUGH Carol C. \& SIHAG Balbir S. The incorporation of multiple bases onto shift-share analysis. Growth and Change, v. 22, n. 1, p. 1-9, winter, 1991. 
PARASKEVOPOULOS, Christos C. The stability of the regional-share component: an empirical test. Journal of Regional Science, v. 11, n. 1, p. 107-112, 1971.

. Analysis and the potential for predicting regional growth patterns: some evidence

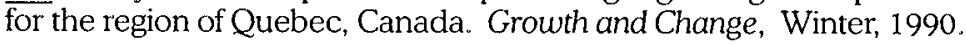

RICHARDSON, Harry W. Economia regional: teoria da localização, estrutura urbana e crescimento regional. Rio de Janeiro, Zahar, 1969.

Regional growth theory. London, Macmillan, 1973.

RICHTER, Charles E. The impact of industrial linkages on geographic association. Journal of Regional Science, v. 9, n. 1, p.19-28, 1969.

RIO GRANDE DO SUL. Assembléia Legislativa. Comissão de agricultura e pecuária. Soja. Porto Alegre, 1974.

Secretaria da Agricultura. Coordenadoria Estadual do Planejamento Agrícola. Zoneamento agrícola. Indicação de culturas e disponibilidade de solo a nível de município. Porto Alegre, 1978. 299 p.

Secretaria da Agricultura e Abastecimento; Centro Nacional da Pesquisa do Trigo. $\overline{M a c}$ Crozoneamento agroecológico e econômico do estado do Rio Grande do Sul. Porto Alegre, 1994. $2 \mathrm{v}$.

Secretaria da Coordenação e Planejamento. Atlas socioeconômico do Estado do Rio Grande do Sul. Porto Alegre, 1998.

SANTOS, Milton. Economia espacial: críticas e alternativas. São Paulo, HUCITEC, 1979.

SIHAG, Balbir 83 MACDONOUGH, Carol C. Shif-share analysis: the international dimension. Growthe Change, v. 20, n. 3, p. 80-88, Summer, 1989.

SOUZA, Nali de Jesus. Desenvolvimento econômico. Porto Alegre, Atlas, 1997.

SURICO, Paolo. The agglomeration dilemma: "Should I Stay or Should I Go?" Growth and Change, v. 34, n. 3, p. 261-275, summer, 2003.

STILWELL ,F. J. B. Regional growth and structural adaptation. Urban Studies, v. 6, n. 2, p. 162-178, 1968

TIMMER, C. P. Agriculture and economic development revisited. Agricultural Systems. v.40, p. 21-58, 1992.

VINING, $R$. Interregional variations in economic fluctuations. The Region as an economic entity and certain variations to be observed in the study of systems of regions, American Economic Review, n. 39, p. 89-104, 1949.

ZANDONADI, Renato. Fundamentos técnicos para o diagnóstico da agricultura brasileira. Brasilia, CNA, 1996. 